\title{
In vitro interactions of Candida parapsilosis wild type and lipase deficient mutants with human monocyte derived dendritic cells
}

\author{
István Nagy ${ }^{1 \dagger}$, Kata Filkor ${ }^{1 \dagger}$, Tibor Németh ${ }^{2}$, Zsuzsanna Hamari ${ }^{2}$, Csaba Vágvölgyi ${ }^{2}$ and Attila Gácser ${ }^{2 *}$
}

\begin{abstract}
Background: Candida parapsilosis typically is a commensal of human skin. However, when host immune defense is compromised or the normal microflora balance is disrupted, C. parapsilosis transforms itself into an opportunistic pathogen. Candida-derived lipase has been identified as potential virulence factor. Even though cellular components of the innate immune response, such as dendritic cells, represent the first line of defense against invading pathogens, little is known about the interaction of these cells with invading C. parapsilosis. Thus, the aim of our study was to assess the function of dendritic cells in fighting C. parapsilosis and to determine the role that C. parapsilosis-derived lipase plays in the interaction with dendritic cells.

Results: Monocyte-derived immature and mature dendritic cells (iDCs and mDCs, respectively) co-cultured with live wild type or lipase deficient C. parapsilosis strains were studied to determine the phagocytic capacity and killing efficiency of host cells. We determined that both iDCs and mDCs efficiently phagocytosed and killed $C$. parapsilosis, furthermore our results show that the phagocytic and fungicidal activities of both iDCs and mDCs are more potent for lipase deficient compared to wild type yeast cells. In addition, the lipase deficient C. parapsilosis cells induce higher gene expression and protein secretion of proinflammatory cytokines and chemokines in both DC types relative to the effect of co-culture with wild type yeast cells.

Conclusions: Our results show that DCs are activated by exposure to C. parapsilosis, as shown by increased phagocytosis, killing and proinflammatory protein secretion. Moreover, these data strongly suggest that $C$. parapsilosis derived lipase has a protective role during yeast:DC interactions, since lipase production in wt yeast cells decreased the phagocytic capacity and killing efficiency of host cells and downregulated the expression of host effector molecules.
\end{abstract}

Keywords: Candida, dendritic cell, innate immunity, secreted lipase

\section{Background}

Candida parapsilosis is an emerging human pathogen that is currently the second or third most commonly isolated Candida species from blood cultures worldwide [1-4]. C. parapsilosis typically is a commensal of human skin and is considered to be of low pathogenicity in the setting of intact host barriers. The species is notorious for its capacity to form biofilms on catheters and other implanted devices, for nosocomial spread by hand

\footnotetext{
* Correspondence: gacsera@gmail.com

† Contributed equally

2Department of Microbiology, University of Szeged, Közép fasor 52, H-6726

Szeged, Hungary

Full list of author information is available at the end of the article
}

carriage, and for persistence in the hospital environment $[1,3,5]$. C. parapsilosis is of special concern in critically ill neonates, causing more than one quarter of all invasive fungal infections in low birth weight infants in the UK [6] and North America [7,8], and it is a leading cause of neonatal mortality. In low-birth weight neonates, mortality rates are similar between infants with invasive disease due to C. parapsilosis and C. albicans, 39 vs. $42 \%$, respectively [6]. Hence, detailed knowledge of $C$. parapsilosis interaction with the host has become urgent. However, host immunity to C. parapsilosis infections represents an important, yet understudied area.

\section{Biomed Central}

(c) 2011 Nagy et al; licensee BioMed Central Ltd. This is an Open Access article distributed under the terms of the Creative Commons Attribution License (http://creativecommons.org/licenses/by/2.0), which permits unrestricted use, distribution, and reproduction in any medium, provided the original work is properly cited. 
Recognition and innate immune response against Candida spp. is effected by both professional (eg. macrophages, neutrophils, dendritic cells) [9] as well as semiprofessional (eg. epithelial cells) [10] immune cells. The most potent phagocytic cells of the immune system are neutrophils and macrophages, and they are also considered as the prototypical phagocytic cells of pathogenic Candida [11]. However, the strategic location of antigen-presenting dendritic cells (DC) at epithelial surfaces and in the skin, the primary sites of C. parapsilosis occurrence, places DCs in the first line of defense against invading yeast cells. It has recently been shown that $C$. parapsilosis induces DC fungipod formation [12], which is associated with immune recognition. Importantly the fungipod response is species specific, since the related fungal pathogens $C$. tropicalis and $C$. albicans induce very few and no fungipods, respectively, suggesting significant differences between the response of DCs to different pathogenic Candida species. [12]. At present, the role of DCs in C. parapsilosis pathogenesis, such as the induction of cytokine gene and protein expression, phagocytosis or fungicidal activity by DCs, is poorly understood.

Although the clinical importance of C. parapsilosis is growing, little is known about its virulence factors. Secretion of extracellular hydrolytic enzymes can facilitate disease and lipases have been associated with $C$. parapsilosis virulence [13], however the exact role of this enzyme is still unknown. Putative roles for lipases include the digestion of lipids for nutrient acquisition, adhesion to host cells, synergistic interactions with other enzymes, unspecific hydrolysis, initiation of inflammatory processes by affecting immune cells, and selfdefense by lysing the competing microflora. We previously showed that $C$. parapsilosis secreted lipase impacted the capacity of the fungus to grow in lipid rich medium, to produce biofilm, and to survive in macrophages. The production of lipase was essential for $C$. parapsilosis to attach, invade and damage reconstituted oral epithelium, and to invade host tissues in a murine infection model [13]. Concomitantly, we have evaluated the role of Lip8, a key lipase in C. albicans, and recapitulated our findings that lipases can be important virulence factors in Candida [14].

The aim of our current study is to determine the in vitro interaction of human monocyte-derived DCs with wild type and lipase deficient C. parapsilosis cells. Because immature and mature DCs (iDCs and mDCs, respectively), show selective responsiveness to different immune and cytokine stimuli we used both cell types in our test system. We have determined that both DC types exert phagocytic and fungicidal activities and produce T-helper (h) 1 type cytokines in response to $C$. parapsilosis. Furthermore we analyzed the role of $C$. parapsilosis lipase by using a lipase deficient mutant and compared the phagocytic capacity and proinflammatory protein production of both DC types.

\section{Results}

Human monocyte derived dendritic cells internalize lipase deficient mutant yeast cells more efficiently

Although human DCs can phagocytose and eliminate $C$. albicans cells [15], there is little information regarding the outcome of the interactions between DCs and $C$. parapsilosis cells. Therefore, we examined the ability of human monocyte-derived DCs to phagocytose C. parapsilosis. For this, iDCs and mDCs were incubated in suspension with unopsonized FITC-labeled live $C$. parapsilosis cells for various periods of time, and phagocytosis was quantified as described in Materials and Methods.

Figure $1 \mathrm{~A}$ and $1 \mathrm{~B}$ show that iDCs ingested both wild type and lipase deficient cells after a $1 \mathrm{~h}$ co-incubation. Phagocytosis by DCs occurred as early as $30 \mathrm{~min}$ (data not shown) after co-culture initiation, and after $1 \mathrm{~h}$ $29.4 \%$ of iDC and $24.8 \%$ of $\mathrm{mDC}$ had ingested C. parapsilosis wild type cells (Figure 1D). In contrast, more DCs ingested lipase deficient yeast, resulting in phagocytosis rates of $44 \%$ (iDC) and $54.6 \%(\mathrm{mDC})$ (p value < 0.05 ) relative to wild type yeast in both DC types (Figure 1D). The phagocytic index data show that phagocytic iDCs internalized an average of 3.2 C. parapsilosis wild type yeast cells and mDCs ingested an average of 2.6 yeast cells (Figure 1E). The lack of the lipase production significantly enhanced DC phagocytic index resulting in average indices of 5.7 and 4.6 for iDCs and $\mathrm{mDCs}$, respectively ( $\mathrm{p}$ value $<0.05$ ) relative to wild type yeast (Figure 1E). To validate and further quantify the phagocytosis percentages of DCs, we also analyzed C. parapsilosis phagocytosis by human DCs using FACS. The FACS results correlated to that achieved by microscopy. FACS showed that $29 \%$ of iDCs phagocytosed wild type C. parapsilosis yeast cells and $47 \%$ ingested lipase deficient yeast cells (Figure 1C). Similarly, 27\% of mDCs ingested wild type yeast cells and 51\% phagocytosed lipase deficient yeast cells (Figure 1C).

\section{iDCs and mDCs efficiently kill C. parapsilosis yeast cells}

To assess whether phagocytosis of C. parapsilosis cells results in the activation of the antifungal effector machinery in iDCs and mDCs, we performed killing assays using DC co-cultures with C. parapsilosis wild type and lipase deficient yeast. The results (Figure. $1 \mathrm{~F}$ ) showed that both iDCs and mDCs were able to efficiently kill C. parapsilosis by $3 \mathrm{~h}$ post-infection. iDCs and mDCs killed $12 \%$ and $13.2 \%$ of wild type C. parapsilosis yeast cells, respectively. Furthermore, we found that $23 \%$ and $38.3 \%$ of lipase deficient yeast cells were killed 


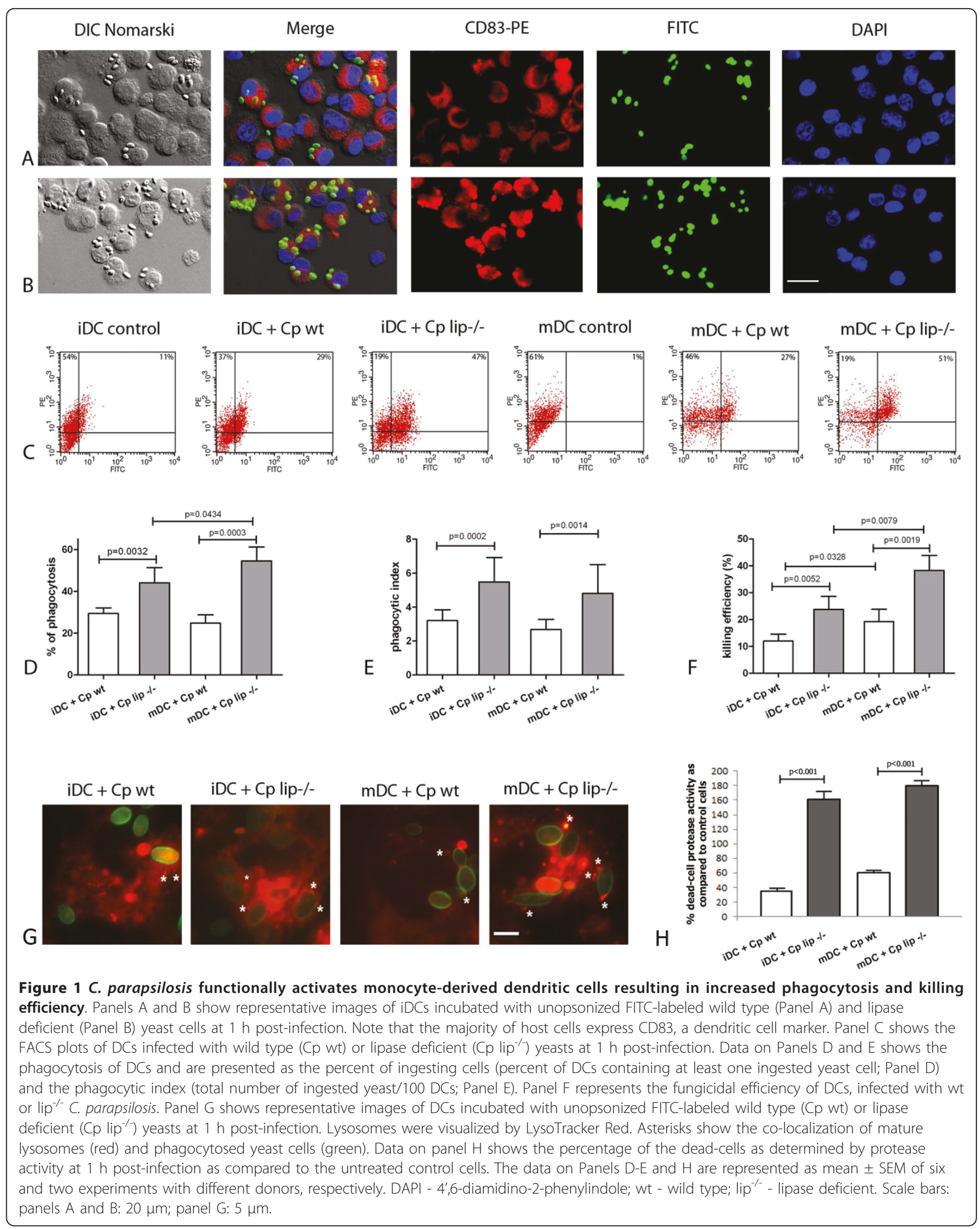


by iDCs and $\mathrm{mDCs}$, respectively, which was significantly higher compared to that of the wild type C. parapsilosis ( $\mathrm{p}$ value $<0.05$ )

In another series of experiments, we have monitored the viability of DCs after infection with C. parapsilosis by measuring the protease activity of the co-cultures. Strikingly, we have found significantly increased number of dead DCs following infection with lipase deficient yeasts compared to uninfected DCs. Increased numbers of dead DCs were present as early as $1 \mathrm{~h}$ post-lipase deficient infection (Figure $1 \mathrm{H}$ ) with only $\sim 10 \%$ of DCs remaining viable $24 \mathrm{~h}$ post-infection (data not shown). In contrast, DCs infected with wild type yeast cells showed decreased protease activity after $1 \mathrm{~h}$ of co-incubation (Figure $1 \mathrm{H}$ ) with $\sim 50 \%$ of DCs still viable at $24 \mathrm{~h}$ post-infection. We have obtained similar results when using Trypan blue labeling (data not shown).

Numerous species of the Candida genus form pseudohyphae as an effort to avoid killing by phagocytic cells. Our data demonstrate that DCs less efficiently kill lipase deficient compared to wild type C. parapsilosis and suggest that wild type yeast cells, at least partially, escape DC immune response. A possible escape mechanism could be pseudohyphae formation. We have monitored the pseudohyphae formation of C. parapsilosis in DCfungi co-culture and determined that $C$. parapsilosis does not form pseudohyphae in our model (Figure 1A, $B$ and data not shown).

Another mechanism by which pathogens modify the immune response of the host is altering lysosome maturation. In order to test if $C$. parapsilosis lipase decreases the phago-lysosome maturation, we have performed labeling with LysoTracker Red, a weakly basic amine that selectively accumulates in acidic compartments such as lysosome. We have observed lysosome maturation in both DC types after infection with wild type and lipase deficient yeast cells (Figure 1G), but there was a decreased number of mature lysosomes in both iDCs and mDCs infected with wild type yeast (Figure 1G).

\section{Production of IL-1 $\alpha$, IL- 6 , TNF $\alpha$, and CXCL8 by iDCs and $\mathrm{mDCs}$ exposed to wild type or lipase deficient $C$. parapsilosis}

The outcome of encounters between antigen-bearing APCs and naive T cells depends, in part, on the nature of the proinflammatory proteins released locally by the APCs. Proinflammatory cytokines and chemokines, such as IL-1 $\alpha$, IL-6, TNF $\alpha$, and CXCL8, secreted by various cell types play a fundamental role in attracting neutrophils and $\mathrm{T}$ cells to the place of skin infection. Therefore, we determined the pattern of the production of the above mentioned four molecules in DCs exposed to wild type or lipase deficient $C$. parapsilosis by monitoring gene expression and protein secretion using qualitative real-time (QRT)-PCR, cytokine-specific ELISAs, and Luminex Fluorokine Multianalyte Profiling (MAP) assays.

For gene expression studies, cells were harvested at 1 and $24 \mathrm{~h}$ post-infection in order to monitor the early and late effects of the infection, respectively. QRT-PCR results revealed that the expression of nearly all of the four proinflammatory genes was significantly higher upon infection with C. parapsilosis cells in comparison to the non-stimulated DC populations $(\mathrm{p}<0.05)$, while the expression of TNF $\alpha$ of iDCs infected with wild type yeast cells and IL- 6 of mDCs were not increased significantly (Figure 2). Although, IL-1 $\alpha$ transcripts were similarly elevated in iDCs at $1 \mathrm{~h}$ post-infection with either wild type or lipase deficient $C$. parapsilosis, the increase was significantly greater with the lipase deficient yeast cells $(\mathrm{p}<0.05)$ (Figure $2 \mathrm{~A})$. At $24 \mathrm{~h}$, the expression levels with either type of $C$. parapsilosis were similarly increased (Figure $2 \mathrm{~B}$ ). In comparison, mDCs stimulated with lipase deficient cells did not show statistically significant upregulation of IL-1 $\alpha$ transcript at $1 \mathrm{~h}$ relative to wild type, however the mRNA level increased by almost 35 fold at $24 \mathrm{~h}(\mathrm{p}<0.05)$. The IL-6 gene was 30 fold upregulated in iDCs infected with lipase deficient cells compared to wild type yeast at $1 \mathrm{~h}$ post-infection $(\mathrm{p}=0.002)$, although there were no differences at $24 \mathrm{~h}$ or during infection of mDCs. Interestingly, the TNF $\alpha$ transcript progressively diminished upon exposure to wild type yeast cells, whereas it was upregulated in iDCs infected with lipase deficient yeast cells. Lipase deficient yeast induced significantly higher CXCL8 gene expression at both time points in iDCs $(\mathrm{p}<0.05)$, whereas mDCs increased CXCL8 mRNA levels only at $24 \mathrm{~h}$ post-infection $(\mathrm{p}<0.05)$.

For protein measurements, cell culture supernatants were collected at 24 and $48 \mathrm{~h}$ post-infection in order to allow protein translation to occur. We detected significantly higher amounts of IL- $1 \alpha$ in co-cultures of lipase deficient cells and iDC at $24 \mathrm{~h}$ ( $\mathrm{p}$ value $<0.05$ ), but this difference was not significant at $48 \mathrm{~h}$ (Table 1). In contrast, $\mathrm{mDCs}$ infected with lipase deficient yeast secreted significantly more IL- $1 \alpha$ protein at both time points ( $p$ value $<0.05$ ) (Table 2). Consistent with the gene expression, we detected high levels of secreted IL- 6 in both iDCs (Table 1) and mDCs (Table 2) at 24 and 48 hours. Similarly, an elevated secretion of TNF $\alpha$ occurred in response to lipase deficient cells at both time points with iDCs (Table 1); however, mDCs produced more TNF $\alpha$ only after $24 \mathrm{~h}$ (Table 2 ). Comparable levels of CXCL8 were measured at $24 \mathrm{~h}$ and $48 \mathrm{~h}$ after exposure to wild type or lipase deficient cells by both DC populations (Table 1 and 2). These results indicate that, upon exposure to $C$. parapsilosis wild type or lipase deficient yeast, iDCs and mDCs differentially produce IL- $1 \alpha$, IL- 6 and TNF $\alpha$. 


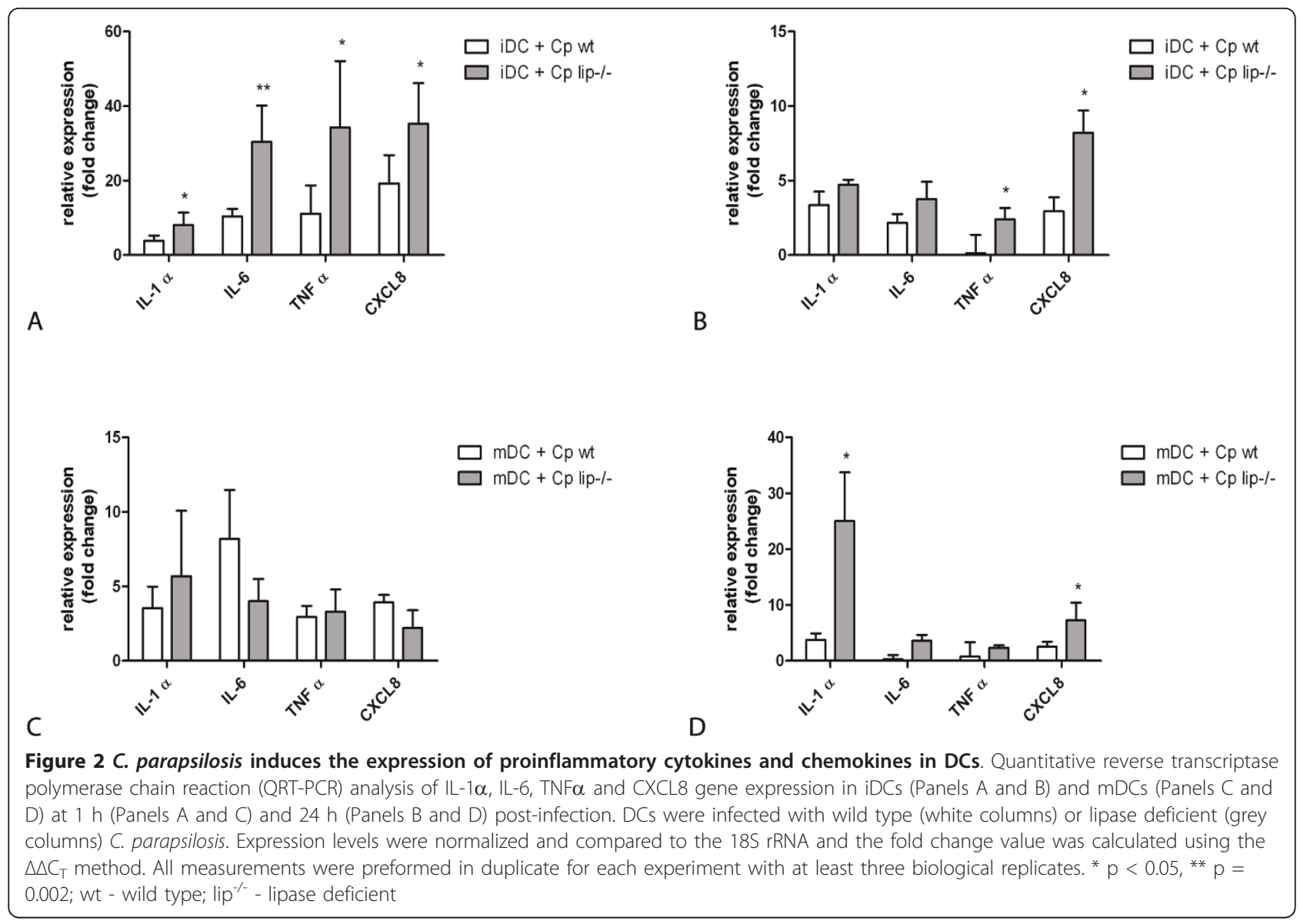

\section{Discussion}

The phagocytic capacity of macrophages and dendritic cells is an important feature during microbial infection, because the outcome of the interaction of phagocytic cells with fungal pathogens influences the susceptibility of the host to the infection $[16,17]$. In this work we demonstrate that the emerging fungal pathogen C. parapsilosis can be efficiently phagocytosed and killed by human monocyte derived dendritic cells. Our results showed that after $1 \mathrm{~h}$ co-incubation $29.4 \%$ of iDC and $24.8 \%$ of $\mathrm{mDC}$ had ingested C. parapsilosis wild type cells. Interestingly, in a comparable study, approximately

Table 1 The profile of proinflammatory cytokine and chemokine secretion of iDCs in response to C. parapsilosis

\begin{tabular}{|c|c|c|c|}
\hline & & iDC (24 h) & \\
\hline$(\mathrm{pg} / \mathrm{ml})$ & unstimulated & $C p$ wt & Cp lip-/- \\
\hline IL-1 $\alpha$ & $9.38^{\dagger}(8.20-11.19)$ & $10.01(8.34-11.17)$ & $23.60^{\#}(19.88-26.74)$ \\
\hline IL-6 & $175.77(48.34-252.62)$ & $3059.61(1689.8-5880.12)$ & $5636.54^{\#}(2792.25-7915.07)$ \\
\hline TNF $\alpha$ & $74.36(55.71-115.78)$ & 624.47 (522.57-736.08) & $2836.59^{\#}(2822.29-3147.02)$ \\
\hline \multirow[t]{2}{*}{ CXCL8 } & 794.23 (162.80-1226.77) & $3622.8(2047-5297.31)$ & 3023.9 (1226.41-5297.31) \\
\hline & & iDC (48 h) & \\
\hline$(\mathrm{pg} / \mathrm{ml})$ & unstimulated & $C p$ wt & Cp lip-/- \\
\hline IL-1 $\alpha$ & $7.85(5.05-12.31)$ & $15.45(8.34-21.56)$ & $22.14(19.88-26.74)$ \\
\hline IL-6 & $3573.23(3201.12-4752.01)$ & $5238.9(3767.13-6082.85)$ & $6968.16^{\#}(5398-8938.58)$ \\
\hline TNF $\alpha$ & $154.92(115.71-194.82)$ & $2342.12(649.76-4333.62)$ & $3947.27^{\#}(2433.01-5393.78)$ \\
\hline CXCL8 & $1103.05(656.02-1473.77)$ & $1615.33(942.11-1756.85)$ & $1824.31(1226.41-2491.06)$ \\
\hline
\end{tabular}

$\mathrm{n}=8$ independent blood donors

Immature dendritic cells were stimulated with C. parapsilosis wild type (Cp wt), lipase deficient (Cp lip-/-) cells or left unstimulated. Secretion of IL-1 $\alpha$, IL-6, TNF $\alpha$ or CXCL8 by iDCs was determined by Luminex analyzer or ELISA at $24 \mathrm{~h}$ and $48 \mathrm{~h}$ post-infection. $\dagger$ : medians (interquartile ranges) \# $\mathrm{p}<0.05$ 
Table 2 The profile of proinflammatory cytokine and chemokine secretion of mDCs in response to C. parapsilosis

\begin{tabular}{|c|c|c|c|}
\hline & & $\mathrm{mDC}(24 \mathrm{~h})$ & \\
\hline$(\mathrm{pg} / \mathrm{ml})$ & unstimulated & $C p$ wt & Cp lip-/- \\
\hline IL-1 $\alpha$ & $21.90^{\dagger}(6.64-70.46)$ & $241.71(19.78-366.12)$ & $487.97^{\#}(110.80-548.77)$ \\
\hline IL-6 & $159.26(38.75-226.87)$ & $3934.41(2481.7-6316.06)$ & $6535.23^{\#}(3122.14-9215.14)$ \\
\hline TNF $\alpha$ & 99.51 (58.12-158.89) & 1724.67 (736.08-2859.76) & $3454.13^{\#}(2934.29-4139.50)$ \\
\hline \multirow[t]{2}{*}{ CXCL8 } & $1632.81(1358.45-2897.26)$ & $3420.32(3268-6563.96)$ & 2657.64 (1846.33-3076.52) \\
\hline & & $\mathrm{mDC}(48 \mathrm{~h})$ & \\
\hline$(\mathrm{pg} / \mathrm{ml})$ & unstimulated & $C p$ wt & Cp lip-/- \\
\hline IL-1 $\alpha$ & $22.97(11.17-40.30)$ & $35.58(11.19-68.98)$ & $126.87^{\#}(59.90-198.21)$ \\
\hline IL-6 & $4364.11(4025.97-5410.58)$ & 5873.19 (4767.13-7510.32) & $7988.22^{\#}(6119.10-9893.27)$ \\
\hline TNF $\alpha$ & $124.92(74.93-163.21)$ & 3456.54 (1628.19-5686.98) & $4345.39(2694.78-5426.10)$ \\
\hline CXCL8 & $2223.11(898.14-4978.58)$ & $2605.43(1254.21-5297.94)$ & $2392.44(1226.74-5394.56)$ \\
\hline
\end{tabular}

$\mathrm{n}=8$ independent blood donors.

Mature dendritic cells were stimulated with C. parapsilosis wild type (Cp wt), lipase deficient ( $C p$ lip-/-) cells or left unstimulated. Secretion of IL-1 $\alpha$, IL-6, TNF- $\alpha$ or CXCL8 by iDCs was determined by Luminex analyzer or ELISA at $24 \mathrm{~h}$ and $48 \mathrm{~h}$ post-infection. + : medians (interquartile ranges) \# $\mathrm{p}<0.05$.

$60 \%$ of a given iDC population phagocytose C. albicans [9] thus, C. parapsilosis cells induce less phagocytosis in comparison to C. albicans. In addition, we also observed that lipase deficient $C$. parapsilosis cells were more efficiently ingested by iDCs and mDCs relative to wild type yeast. The microscopy and FACS results demonstrating avid DC phagocytosis of both wild type and lipase deficient yeast is consistent with an activated phenotype of these host effector cells. Moreover, the enhanced phagocytosis of lipase deficient C. parapsilosis by DCs relative to wild type yeast cells suggests that lipase interferes with efficient DC activation.

Dendritic cells are able to kill internalized fungal cells. The in vitro infections of DCs resulted in a $12 \%$ killing of C. parapsilosis wild type cells. This result is comparable with that of C. albicans (13.6 \pm SD 5.4\%) [15]. Moreover, DCs did not kill C. albicans cells as efficiently as monocytes or macrophages [15], and the $C$. albicans findings and our results are consistent with the concept that the function of DC is to present candidal antigens to $\mathrm{T}$-cells [18] rather than to eliminate the microorganism. Notably, our data showed a significantly elevated killing capacity of human dendritic cells against lipase deficient C. parapsilosis strain. In summary, DCs can effectively phagocytose C. parapsilosis, but the capacity to kill the yeast cells is less than that of macrophages [19] and according to our recent results, fungal lipase suppresses the fungicidal activity of DCs.

The mechanisms involved in intracellular pathogenesis are diverse. Among fungi, the most studied intracellular pathogen is Histoplasma capsulatum, which is able to impair phagosome-lysosome fusion [20,21]. In the case of $C$. parapsilosis wild type strain, we observed that there is a defect in the maturation of the DC phagolysosome using lysosomal markers of this process. This finding is in agreement with the related species C. albicans, where alterations of phagosome maturation and acidification defects have been described [22,23]. The lipase deficient mutants showed higher co-localization with lysotracker stain, suggesting more frequent phagolysosome fusion and compartment acidification. In addition, our findings highlight that secreted fungal lipases appear to have a role in the protective mechanisms against the host intracellular killing processes.

The immune system may be activated by the recognition of nonself molecules of infectious agents or by recognition of danger signals that include host molecules released by damaged host cells [24]. It is proposed that the two models are compatible, which may also be the case in our model: both $C$. parapsilosis strains induced the expression of chemotactic molecules, in addition, DCs infected with lipase deficient yeast showed increased cell death which is known to be accompanied by the release of danger signals [25]. Consequently, we propose that DCs infected with lipase deficient yeast cells activate more robust immune response.

Although both wild type and lipase deficient C. parapsilosis induced strong, time-dependent activation of pro-inflammatory genes such as IL-1 $\alpha$, IL- 6, TNF- $\alpha$, and CXCL- 8 in both DC types, lipase deficient yeast induced significantly higher gene expression of effector molecules. Since locally produced chemotactic factors are presumed to mediate the sequence of events leading to the infiltration of immune cells at inflammatory sites, local expression of pro-inflammatory mediators after contact with $C$. parapsilosis could have an initiator role in the attraction of additional immune cells to the sites of infection. This is supported by the fact that CXCL8 is one of the most potent neutrophil chemoattractants [26] that affects not only the recruitment of neutrophils into the tissues but also modulates the ability of these neutrophils to cross epithelial barriers and to kill pathogens. In addition, TNF- $\alpha$ enhances the fungicidal properties of neutrophils, promotes the adhesion of immune to 
endothelial cells and acts as a danger signal. Corresponding to this finding, we found that DCs infected with lipase deficient yeast cells displayed increased protease activity, which accompanies cell death and the release of danger signals. Finally, TNF- $\alpha$, IL- $1 \alpha$ and IL- 6 are also implicated in the induction of antimicrobial peptide expression in epithelial cells [27]. Taken together, the secretion of pro-inflammatory mediators and the release of danger signals by DCs as a response to $C$. parapsilosis may play a crucial role in the recruitment of immune cells into the sites of infection.

\section{Conclusions}

Our work shows that C. parapsilosis activates monocytederived DCs, as demonstrated by increased phagocytosis and killing of yeast cells and proinflammatory protein secretion. Moreover, we found that DCs infected with lipase deficient C. parapsilosis are functionally more potent relative to DCs infected with wild type yeast cells, which suggests that lipase interferes with DC activation. This finding was unexpected because lipases of other pathogenic microorganisms are considered to be inducers of immune response, consequently one would have predicted a decreased activation phenotype in response to lipase deficient C. parapsilosis. The fact that this was not the case appears to result, at least in part, the DC activation is suppressed by the C. parapsilosis lipase. Further studies will be required to identify the defective anti-C. parapsilosis effector mechanisms that increase susceptibility to invasive candidiasis and to determine how $C$. parapsilosis lipase represses immune activation.

\section{Methods}

Fungal Strains and culture conditions

Candida parapsilosis GA1 and lipase deficient ( $\triangle$ Cplip1$\Delta$ Cplip2/ $\triangle$ Cplip1- $\triangle$ Cplip2::FRT) strains [13] were maintained at $-80^{\circ} \mathrm{C}$ in $35 \%$ glycerol. If not mentioned otherwise, the cells were grown in YPD (1\% yeast extract, $2 \%$ bactopeptone, $2 \%$ glucose).

\section{Monocyte isolation and dendritic cell differentiation}

Human peripheral blood mononuclear cells (PBMCs) were isolated from buffy coat blood samples from healthy donors by Ficoll Paque Plus (GE Healthcare) density gradient centrifugation. Monocytes were isolated by adherence on tissue culture plastic plates. Immature dendritic cells were prepared by culturing monocytes for five days with $1000 \mathrm{U} / \mathrm{ml}$ human recombinant granulocyte-macrophage colony stimulating factor (GM-CSF; Sigma) and $1000 \mathrm{U} / \mathrm{ml}$ human recombinant interferon- $\alpha$ (IFN- $\alpha$; Sigma) in RPMI-1640 medium (Gibco) complemented with 10\% heat-inactivated FBS (Gibco) and 1\% penicillin/streptomycin solution (Gibco) in 6-well tissue culture plate (Sarstedt). Mature dendritic cells were obtained from immature dendritic cells by stimulation with $10 \mathrm{ng} / \mathrm{ml}$ recombinant TNFa (R\&D Systems) for 24 hours.

\section{In vitro infection}

For infections, iDC and $\mathrm{mDC}$ cells were co-incubated with C. parapsilosis cells at effector-to-target ratios of 1:5 in six-well plates. Samples were incubated for various time at $37^{\circ} \mathrm{C}$ and $5 \%(\mathrm{v} / \mathrm{v}) \mathrm{CO}_{2}$. For gene expression studies DCs were harvested after $1 \mathrm{~h}$ and $24 \mathrm{~h}$ coincubations, for cytokine measurement supernatants were collected after $24 \mathrm{~h}$ and $48 \mathrm{~h}$.

\section{Killing assays}

Co-cultures of the DCs and C. parapsilosis were performed according to our described protocol [13] with some modifications. Briefly, C. parapsilosis cells were grown overnight, washed three times in PBS, counted using a hematocytometer, and suspended in RPMI-1640 medium (Gibco). The cells were then co-incubated with DCs as described above. As a control, the same number of C. parapsilosis cells were inoculated in the RPMI1640 medium (Gibco) complemented with 10\% heatinactivated FBS (Gibco) and 1\% penicillin/streptomycin solution (Gibco) with no effector cells. The wells were then incubated at $37^{\circ} \mathrm{C}$ for $3 \mathrm{~h}$, and washed three times with PBS to remove nonadherent Candida cells. Yeast cells were liberated from DCs by forcibly disrupting the DCs through pipetting them in distilled water for $2 \mathrm{~min}$. The yeast cells were collected, counted, and serially diluted prior to being plated. Cells were plated in YPD agar and incubated for 3 days at $30^{\circ} \mathrm{C}$. The killing efficiency was calculated by normalizing the number of CFU (colony forming unit) counted from the DC infected wells to the total number of CFU of $C$. parapsilosis detected from the control wells, and multiplied by 100 for percentage.

\section{Phagocytosis assays}

Infections were performed as described above and the phagocytosis was monitored by fluorescent microscope after $1 \mathrm{~h}$ of co-incubation. Briefly, DCs were treated with FITC-labeled C. parapsilosis wild type or homozygous lipase deletion mutant for $1 \mathrm{~h}$. Cells were then trypsinized by using TrypLe Express (Gibco), and washed with PBS. The fluorescence of extracellular yeasts was quenched with $0,4 \%$ Trypan blue solution. In some experiments labelling with calcofluor white $(0,1$ $\mathrm{ng} / \mathrm{ml}(\mathrm{w} / \mathrm{v}))$ was also performed in order to define nonphagocytosed yeast cells (data not shown). After two washes with PBS, cell suspensions were loaded up in each cuvette of a cytospin (Cellspin I, Tharmac). The cells were collected at $600 \mathrm{rpm}$ for 6 minutes and then fixed in PBS with $4 \%$ paraformaldehyde for $15 \mathrm{~min}$. The 
samples were then permeabilized with PBS containing 1\% Triton-X (Sigma) for 30 minutes and blocked in PBS containing 1\% BSA for 20 minutes. Samples were incubated with 1:10 dilution of phycoeritrin (PE) conjugated anti-CD83 antibody (Life Technologies) in PBS containing $1 \% \mathrm{BSA}$ and $0.1 \%$ Triton-X for $1 \mathrm{~h}$ and washed three times with PBS for 5 min each. Negative controls consisted of incubation with isotype matched control (Life Technologies). Finally, samples were washed with PBS containing 4',6-diamidino-2-phenylindole (DAPI) and mounted in Citifluor mounting media (Citifluor Ltd.). Samples were analyzed using epifluorescent illumination of the Axiovision Z1 Fluorescent Microscope (Zeiss) and images recorded by Axiovision software. The percent of phagocytosis was the ratio of the number of DCs that ingested yeast to the total number of DCs multiplied by 100. Phagocytic index was the ratio of the number of intracellular yeast cells to the number of DCs which phagocytozed at least one yeast cell. The number of total DCs, DCs containing yeast cells and ingested C. parapsilosis cells were determined from ten individual fields.

\section{Flow cytometry analysis}

Treatment and harvesting of DCs with FITC-labeled $C$. parapsilosis strains was performed as described above. The fluorescence of extracellular yeasts was quenched with $0,4 \%$ Trypan blue solution. Cells were washed twice with FACS buffer (2\% FBS and 0,5 mM EDTA in PBS). Cells were then incubated with 1:10 dilution of phycoeritrin conjugated anti-CD83 antibody or an isotype matched control (Life Technologies) for 30 minutes at $4{ }^{\circ} \mathrm{C}$. Cells were fixed with FACS fix solution (2\% FBS, 0,5 mM EDTA and 4\% paraformaldehyde in PBS) and analyzed on a FACS Calibur Flow Cytometer (Becton Dickinson) using CellQuest Pro software.

\section{Lysosome maturation assays}

Infections were performed as described above and lysosome maturation was monitored by fluorescent microscopy after $1 \mathrm{~h}$ of co-incubation. Briefly, DCs were treated with wild type or a homozygote lipase deletion mutant FITC-labeled C. parapsilosis. After $1 \mathrm{~h}$ co-incubation the cell culture media was replaced by fresh media supplemented with 50nM LysoTracker Red (Life Technologies) and incubated for additional 45 minute. Cells were then spun and mounted as described in phagocytosis assay section. Samples were analyzed using epifluorescent illumination of the Axiovision Z1 Fluorescent Microscope (Zeiss) and images recorded by Axiovision software.

\section{Cell viability assays}

Treatment and harvesting of DCs with C. parapsilosis strains was performed as described above. After 1 and 24 hours co-incubation, cells were transferred into 96- well U-bottom opaque plate (Greiner). Dead-cell protease activity was measured using Cyto Tox-Glo Cytotoxicity Assay (Promega) following the manufacturer's instructions. Luciferase activity was measured by microplate luminometer (LUMIStar Optima, BMG Labtech).

\section{Quantitative reverse transcriptase polymerase chain reaction (QRT-PCR)}

Total RNA was extracted from DCs using RNeasy Plus Mini Kits (Qiagen) according to the manufacturer's instruction. The quality and quantity of the extracted RNA was determined using NanoDrop (Thermo Scientific), Qubit (Life Technologies) and Bioanalyzer (Agilent) measurements. cDNA was synthesized from 150ng of total RNA by using High Capacity RNA to cDNA Kit (Life Technologies) on a Veriti Thermal Cycler (Life Technologies). TaqMan technology based real-time quantitative PCR was used to quantify the relative abundance of each mRNA (StepOne Plus Real-Time PCR System; Life Technologies). For this, specific exon spanning gene expression assays were used for IL-1 $\alpha$ (Hs00174092_m1), IL-6 (Hs00174131_m1), TNFa (Hs00174128_m1), CXCL8 (Hs00174103_m1) and 18S rRNA (Hs99999901). As controls, we used the reaction mixtures without the cDNA. All measurements were preformed in duplicate for each experiment with at least three biological replicates. The ratio of each mRNA relative to the $18 \mathrm{~S}$ rRNA was calculated using the $\Delta \Delta C_{\mathrm{T}}$ method.

\section{Measurement for secreted cytokine levels}

Harvested cell culture supernatants were centrifuged and the concentrations of secreted IL- $1 \alpha$, IL- 6 and TNF- $\alpha$ were measured by Fluorokine Multianalyte Profiling (MAP) Kits (R\&D Systems, Inc.) on a Luminex analyzer (Luminex Corp.), according to the manufacturer's instruction. CXCL8, IL- $1 \alpha$, IL- 6 and TNF $\alpha$ proteins were also measured using the Quantikine human immunoassay kits (R\&D Systems, Inc.) following the manufacturer's instructions. We used serial dilutions of the respective recombinant human proteins for generating standard curves. The optical density of the wells was determined using a microplate reader (FLUOstar Optima, BMG Labtech) set to $450 \mathrm{~nm}$ with a wavelength correction set to $540 \mathrm{~nm}$.

\section{Statistical analysis}

The significance of differences between sets of data was determined by Newman-Keuls test or ANOVA according to the data by using GraphPad Prism version 5.02 for Windows (California, USA).

\section{Acknowledgements and Funding}

The authors sincerely thank Dr. Joshua D. Nosanchuk for his critical reading of the manuscript. AG is supported by OTKA PD73250 and by EMBO 
Installation Grant 1813. AG and ZH are supported by the János Bolyai Research Scholarship of the Hungarian Academy of Sciences. IN was supported by the Hungarian National Office for Research and Technology Teller program OMFB-00441/2007. IN and FK are also supported by the French-Hungarian Associated European Laboratory (LEA) SkinChroma OMFB$00272 / 2009$

\section{Author details}

1 Institute for Plant Genomics, Human Biotechnology and Bioenergy, Bay Zoltán Foundation for Applied Research, Derkovits fasor 2., 6726 Szeged, Hungary. ${ }^{2}$ Department of Microbiology, University of Szeged, Közép fasor 52, H-6726 Szeged, Hungary.

\section{Authors' contributions}

FK, TN and AG carried out the phagocytosis and QRT-PCR studies, participated in the protein measurement experiments. ZSH, IN and AG participated in the infection studies. IN and AG participated in the design of the study and performed the statistical analysis. IN, CV and AG conceived of the study, and participated in its design and coordination and helped to draft the manuscript. All authors read and approved the final manuscript.

\section{Competing interests}

The authors declare that they have no competing interests.

Received: 18 January 2011 Accepted: 29 May 2011

Published: 29 May 2011

\section{References}

1. van Asbeck EC, Clemons KV, Stevens DA: Candida parapsilosis: a review of its epidemiology, pathogenesis, clinical aspects, typing and antimicrobial susceptibility. Crit Rev Microbiol 2009, 35:283-309.

2. Pfaller MA, Jones RN, Doern GV, Fluit AC, Verhoef J, Sader HS, Messer SA, Houston A, Coffman S, Hollis RJ: International surveillance of blood stream infections due to Candida species in the European SENTRY Program: species distribution and antifungal susceptibility including the investigational triazole and echinocandin agents. SENTRY Participant Group (Europe). Diagn Microbiol Infect Dis 1999, 35:19-25.

3. Trofa D, Gacser A, Nosanchuk JD: Candida parapsilosis, an emerging fungal pathogen. Clin Microbiol Rev 2008, 21:606-625.

4. Pfaller MA, Moet GJ, Messer SA, Jones RN, Castanheira M: Candida Bloodstream Infections: Comparison of Species Distribution and Antifungal Resistance in Community Onset and Nosocomial Isolates in the SENTRY Antimicrobial Surveillance Program (2008-2009). Antimicrob Agents Chemother 2010.

5. Clark TA, Slavinski SA, Morgan J, Lott T, Arthington-Skaggs BA, Brandt ME, Webb RM, Currier M, Flowers RH, Fridkin SK, Hajjeh RA: Epidemiologic and molecular characterization of an outbreak of Candida parapsilosis bloodstream infections in a community hospital. J Clin Microbiol 2004 42:4468-4472.

6. Clerihew L, Lamagni TL, Brocklehurst P, McGuire W: Candida parapsilosis infection in very low birthweight infants. Arch Dis Child Fetal Neonatal Ed 2007, 92:F127-129.

7. Benjamin DK Jr, Garges H, Steinbach WJ: Candida bloodstream infection in neonates. Semin Perinatol 2003, 27:375-383.

8. Smith PB, Steinbach WJ, Benjamin DK Jr: Neonatal candidiasis. Infect Dis Clin North Am 2005, 19:603-615.

9. Newman SL, Holly A: Candida albicans is phagocytosed, killed, and processed for antigen presentation by human dendritic cells. Infect Immun 2001, 69:6813-6822

10. Pivarcsi A, Bodai L, Rethi B, Kenderessy-Szabo A, Koreck A, Szell M, Beer Z, Bata-Csorgoo Z, Magocsi M, Rajnavolgyi E, Dobozy A, Kemeny L: Expression and function of Toll-like receptors 2 and 4 in human keratinocytes. Int Immunol 2003, 15:721-730.

11. Netea MG, Brown GD, Kullberg BJ, Gow NA: An integrated model of the recognition of Candida albicans by the innate immune system. Nat Rev Microbiol 2008, 6:67-78.

12. Neumann AK, Jacobson K: A novel pseudopodial component of the dendritic cell anti-fungal response: the fungipod. PLOS Pathog 2010, 6 e1000760
13. Gacser A, Trofa D, Schafer W, Nosanchuk JD: Targeted gene deletion in Candida parapsilosis demonstrates the role of secreted lipase in virulence. J Clin Invest 2007, 117:3049-3058.

14. Gacser A, Stehr F, Kroger C, Kredics L, Schafer W, Nosanchuk JD: Lipase 8 affects the pathogenesis of Candida albicans. Infect Immun 2007, 75:4710-4718.

15. Netea MG, Giizen K, Coolen N, Verschueren I, Figdor C, Van der Meer JW, Torensma R, Kullberg BJ: Human dendritic cells are less potent at killing Candida albicans than both monocytes and macrophages. Microbes Infect 2004, 6:985-989

16. Shao X, Mednick A, Alvarez M, van Rooijen N, Casadevall A, Goldman DL: An innate immune system cell is a major determinant of species-related susceptibility differences to fungal pneumonia. J Immunol 2005 , 175:3244-3251.

17. Zaragoza O, Alvarez M, Telzak A, Rivera J, Casadevall A: The relative susceptibility of mouse strains to pulmonary Cryptococcus neoformans infection is associated with pleiotropic differences in the immune response. Infect Immun 2007, 75:2729-2739.

18. Colonna M, Pulendran B, Iwasaki A: Dendritic cells at the host-pathogen interface. Nat Immunol 2006, 7:117-120.

19. Gacser A, Salomon S, Schafer W: Direct transformation of a clinical isolate of Candida parapsilosis using a dominant selection marker. FEMS Microbiol Lett 2005, 245:117-121.

20. Eissenberg LG, Goldman WE, Schlesinger PH: Histoplasma capsulatum modulates the acidification of phagolysosomes. J Exp Med 1993 177:1605-1611

21. Shi L, Albuquerque PC, Lazar-Molnar E, Wang X, Santambrogio L, Gacser A Nosanchuk JD: A monoclonal antibody to Histoplasma capsulatum alters the intracellular fate of the fungus in murine macrophages. Eukaryot Cell 2008, 7:1109-1117.

22. Fernandez-Arenas E, Bleck CK, Nombela C, Gil C, Griffiths G, Diez-Orejas R: Candida albicans actively modulates intracellular membrane trafficking in mouse macrophage phagosomes. Cell Microbiol 2009, 11:560-589.

23. Marcil A, Gadoury C, Ash J, Zhang J, Nantel A, Whiteway M: Analysis of PRA1 and its relationship to Candida albicans- macrophage interactions. Infect Immun 2008, 76:4345-4358.

24. Lazzaro BP, Rolff J: Immunology. Danger, microbes, and homeostasis. Science 2011, 332:43-44.

25. Matzinger P: The danger model: a renewed sense of self. Science 2002 296:301-305.

26. Strieter RM, Kunkel SL, Showell HJ, Remick DG, Phan SH, Ward PA Marks RM: Endothelial cell gene expression of a neutrophil chemotactic factor by TNF-alpha, LPS, and IL-1 beta. Science 1989, 243:1467-1469.

27. Liu AY, Destoumieux D, Wong AV, Park CH, Valore EV, Liu L, Ganz T: Human beta-defensin-2 production in keratinocytes is regulated by interleukin1, bacteria, and the state of differentiation. J Invest Dermatol 2002, 118:275-281.

doi:10.1186/1471-2180-11-122

Cite this article as: Nagy et al:: In vitro interactions of Candida parapsilosis wild type and lipase deficient mutants with human monocyte derived dendritic cells. BMC Microbiology 2011 11:122.

\section{Submit your next manuscript to BioMed Central and take full advantage of:}

- Convenient online submission

- Thorough peer review

- No space constraints or color figure charges

- Immediate publication on acceptance

- Inclusion in PubMed, CAS, Scopus and Google Scholar

- Research which is freely available for redistribution

Submit your manuscript at www biomedcentral com/submit
C Biomed Central 